\title{
Association between Risk Factors for Vascular Dementia and Adiponectin
}

\author{
Juhyun Song, ${ }^{1}$ Won Taek Lee, ${ }^{1}$ Kyung Ah Park, ${ }^{1}$ and Jong Eun Lee ${ }^{1,2}$ \\ ${ }^{1}$ Department of Anatomy, Yonsei University College of Medicine, 50 Yonsei-ro, Seoul 120-752, Republic of Korea \\ ${ }^{2}$ BK21 Plus Project for Medical Sciences and Brain Research Institute, Yonsei University College of Medicine, 50 Yonsei-ro, \\ Seodaemun-gu, Seoul 120-752, Republic of Korea
}

Correspondence should be addressed to Jong Eun Lee; jelee@yuhs.ac

Received 24 January 2014; Revised 27 March 2014; Accepted 30 March 2014; Published 17 April 2014

Academic Editor: Xiaokun Li

Copyright (C) 2014 Juhyun Song et al. This is an open access article distributed under the Creative Commons Attribution License, which permits unrestricted use, distribution, and reproduction in any medium, provided the original work is properly cited.

\begin{abstract}
Vascular dementia is caused by various factors, including increased age, diabetes, hypertension, atherosclerosis, and stroke. Adiponectin is an adipokine secreted by adipose tissue. Adiponectin is widely known as a regulating factor related to cardiovascular disease and diabetes. Adiponectin plasma levels decrease with age. Decreased adiponectin increases the risk of cardiovascular disease and diabetes. Adiponectin improves hypertension and atherosclerosis by acting as a vasodilator and antiatherogenic factor. Moreover, adiponectin is involved in cognitive dysfunction via modulation of insulin signal transduction in the brain. Case-control studies demonstrate the association between low adiponectin and increased risk of stroke, hypertension, and diabetes. This review summarizes the recent findings on the association between risk factors for vascular dementia and adiponectin. To emphasize this relationship, we will discuss the importance of research regarding the role of adiponectin in vascular dementia.
\end{abstract}

\section{Introduction}

Vascular dementia is the second most common type of dementia, accounting for 15 to $20 \%$ of all cases of dementia [1]. It is characterized by cognitive impairment and cerebrovascular pathologies [2]. According to the World Alzheimer Report 2011, an estimated 36 million people worldwide were afflicted with dementia. This number is increasing twofold every 20 years and will likely reach 115 million people by $2050[3,4]$. Among the subtypes of dementia, vascular dementia is important because it results from a variety of causes, including cerebrovascular dysfunction. Vascular dementia and cerebrovascular diseases have common risk factors including hypertension, insulin resistance, diabetes, obesity, hyperhomocystinemia, and hyperlipidemia [5-8]. Recent clinical-pathological studies have focused on cognitive impairment and increased risk of dementia in patients with cerebrovascular disease $[2,9,10]$. In addition, vascular dementia is the most severe form of vascular cognitive impairment (VCI) [2, 11], and it results from subclinical vascular brain injury and stroke. VCI reflects the full range of cognitive alterations due to vascular factors [12].
A previous study demonstrates that reducing vascular risk factors inhibits cognitive decline progression [12]. Type 2 diabetes mellitus (T2DM), a risk factor for vascular dementia, is a heterogeneous metabolic disease characterized by reduced insulin sensitivity and relative insulin deficiency. T2DM and dyslipidemia frequently coexist with vascular dementia [13]. Adiponectin is almost exclusively secreted by adipocytes, and it appears to act as a modulator of anti-inflammation and insulin-sensitizer [14]. Adiponectin has beneficial effects on endothelial cells and affects the progression of stroke, atherosclerosis, and hypertension [1520]. Plasma adiponectin levels are decreased in patients with cardiovascular disease and several metabolic disorders [21]. Several studies reported an inverse relationship between plasma adiponectin and T2DM [22-26]. In this review, we examine current research regarding the relationship between risk factors for vascular dementia and adiponectin.

\section{Risk Factors for Vascular Dementia}

Vascular dementia is regarded as the most severe form of VCI characterized by the presence of clinical stroke or vascular 
brain injury as well as cognitive impairment $[2,11,27]$. Several studies suggest that the risk factors for vascular dementia are almost identical as the risk factors for VCI. Common risk factors in both animal models and humans include hypertension, insulin resistance, hyperlipidemia, hyperhomocystinemia, atherosclerosis, and diabetes [28-32]. Age is also a risk factor for vascular dementia, suggesting that dementia in patients after the age of 65 increased gradually [33]. In addition, cerebrovascular dysfunction is a risk factor because the cerebrovascular function is reduced in patients with dementia [34-42]. In addition, another study suggests that metabolic syndrome, including insulin resistance, hypertension, and dyslipidemia, is associated with cognitive decline, a typical feature of vascular dementia [30]. Figure 1 shows that vascular dementia risk factors include aging, diabetes, hypertension, atherosclerosis, and stroke (Figure 1).

\section{Adiponectin}

Adiponectin is one of the most abundant adipokines [43, 44]. It has significant sequence similarities with complement factor $\mathrm{Clq}$, whose protein is termed Acrp30 because it is a $30 \mathrm{kDa}$ adipocyte complement-related protein $[45,46]$. Adiponectin is the protein produced by adipose's most abundant gene transcript 1 (APM1) gene, and APM1 gene is located on chromosome $3 q 27$, a region associated with T2DM and metabolic syndrome susceptibility [47-50]. Several human genetic association studies emphasized that hypoadiponectinemia caused by the single nucleotides polymorphisms (SNPs) in APM1 gene is important to investigate the role of adiponectin in a variety of diseases $[14,51-54]$ including insulin resistance, T2DM, and metabolic syndrome, such as obesity [55]. In white French subjects, 2 SNPs in the promoter region of APM1 gene, SNP 11377 and SNP 11391, were strongly related to hypoadiponectinemia and T2DM [50]. In white German and North American subjects, the +276 G/T SNP was associated with obesity and insulin resistance $[52,56]$. In Chinese subjects, the $+276 \mathrm{G} / \mathrm{T}$ SNP was significantly involved in the coronary heart disease [57]. Adiponectin acts via binding its receptors, adiponectin receptor type 1 (AdipoR1) and type 2 (AdipoR2). AdipoR1 has a higher binding affinity to the globular form of adiponectin, whereas AdipoR2 has a higher binding affinity to full-length adiponectin [58]. Adiponectin binds to the C-terminal extracellular domain of AdipoR, and the N-terminal cytoplasmic domain interacts with APPL1 [59]. Adiponectin receptors are expressed in liver, hypothalamus, and brain vascular endothelial cells [6062]. Adiponectin is associated with insulin resistance, obesity, T2DM, dyslipidemia, and cardiovascular diseases [63-70]. It is an effective insulin sensitizer $[64,71,72]$, and it promotes peripheral insulin sensitivity [14] and inhibits liver gluconeogenesis [73]. Decreases in circulating adiponectin in the prediabetic state lead to insulin resistance [74]. Adiponectin activates AMP-activated protein kinase (AMPK), which activates insulin-independent glucose uptake by muscle, downregulates gluconeogenic enzymes, and increases muscle fatty acid oxidation [73]. Unlike other adipocyte-derived

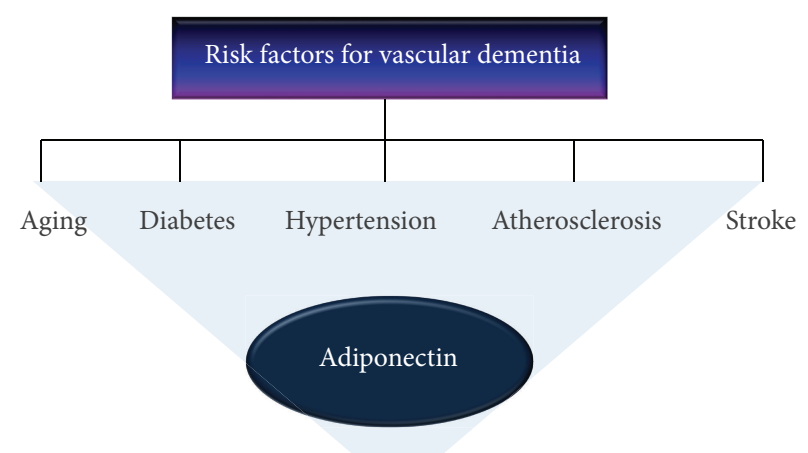

FIGURE 1: Risk factors for vascular dementia and adiponectin. Vascular dementia risk factors include aging, diabetes, hypertension, atherosclerosis, and stroke. Adiponectin is related to aging, diabetes, hypertension, atherosclerosis, and stroke by acting as a modulator or regulator in various mechanisms. Current researches have reported the role of adiponectin in diabetes, hypertension, atherosclerosis, and stroke.

hormones, adiponectin gene expression and plasma concentration are inversely associated with body mass index (BMI) [75]. Reduced plasma adiponectin levels have also been reported in patients with coronary artery disease [19] as well as those with increased carotid intima media thickness [76]. Plasma adiponectin levels are inversely related to the platelet activation status of patients with cardiovascular risk factors [20]. Adiponectin suppresses platelet aggregation in hyperlipidemic rats by reversing the increase in inducible nitric oxide synthase expression while enhancing endothelial nitric oxide synthase activation $[77,78]$. Current studies have reported the association between adiponectin and various diseases because adiponectin has multiple roles in glucose and lipid metabolisms and vascular system.

\section{Adiponectin, Aging, and Diabetes}

4.1. Aging, Insulin Signal Transduction, and Adipocytokines. Recently, the number of elderly patients with dementia has been increasing rapidly [79]. One epidemiology study suggests an exponential increase in the incidence of dementia after the age of 65 , doubling roughly every 5 years, such that greater than $50 \%$ of centenarians are expected to suffer from dementia [33]. Aging induces an oxidative redox shift by attenuating mitochondrial metabolism and changing glycolysis metabolism [80]. These alterations initiate a damaging pathway involving signaling molecules, transcription factors, and epigenetic transcriptional regulators [80, 81]. Among several important pathways for maintaining longevity, insulin sensitivity has been considered a key factor for the healthy aging phenotype in humans $[82,83]$ and mice $[84,85]$. Several studies have reported that insulin and insulin growth factor1 (IGF-1) receptor regulate the lifespan of mice $[86,87]$. In humans, growth hormone $(\mathrm{GH})$ and IGF-1 deficiencies are also associated with life expectancy [88]. Insulin sensitivity normally decreases during aging, and the prevalence of 
metabolic syndrome (MetS) and insulin resistance substantially increases $[89,90]$. In elderly persons, decreased insulin receptor (IR) levels and impaired insulin signaling have been observed predominantly in the hippocampus cortex and choroid plexus [81]. Impaired insulin receptor binding promotes chronic insulin resistance [91]. Muller et al. [92] reported that IGF-I signaling deteriorated in the brains of aged mice. This study demonstrated that activation of the brain IGF-1R/Akt/GSK-3 $\beta$ pathway was evidently reduced although older mice have higher brain IGF-1R levels [92]. In humans, insulin sensitivity decreases with aging and the prevalence of T2DM increases with advancing age [89, 90]. Reduced mitochondrial function contributes to decline in glucose uptake with advancing age and leads to insulin resistance [93-97]. IGF-1 concentrations decline with age and are associated with age-related changes in body composition by both increasing fat mass and decreasing muscle mass [98100]. Aging alters the function and number of adipose cells which cause alterations in the secretion and function of the adipocytokines such as leptin and adiponectin [101]. A recent study demonstrated that cellular senescence of adipose tissue causes insulin resistance [102]. Considering these evidences, aging alters the function of adipose cells, and alteration in secretion of adipocytokines attenuates insulin sensitivity.

4.2. Adiponectin and Insulin Signal Transduction. Insulin and IRs are ubiquitously expressed in the brain [81, 103] where insulin can reach levels 10 - to 100 -fold greater than in plasma, particularly in the hippocampus, cortex, hypothalamus, olfactory bulb, and pituitary [81, 104]. IRs are largely localized in neurons and are less abundant in glia $[103,105]$. Insulin produced by pancreatic $\beta$-cells is transported by cerebrospinal fluid (CSF) to the brain where it crosses the blood-brain barrier (BBB) $[106,107]$. Similar to IRs, IGF-1Rs are widely distributed in the brain [107, 108]. Insulin/IGF-1-mediated activation of Akt leads to GSK-3 $\beta$ inactivation, which triggers multiple cascades, including synthesis of proteins involved in neuronal glucose metabolism and antiapoptotic mechanisms [104, 109]. Regarding brain glucose metabolism, recent studies suggest that changes in circulating insulin levels modulate glucose transporter (GLUT) expression [110, 111]. Cerebral IRs and IGF-1Rs are involved in cortical and hippocampal synaptic plasticity, thereby affecting memory and learning $[105,112]$. In brain, insulin contributes to memory function through regulation of neurotransmitter receptors and synaptic function [113, 114]. Additionally, insulin signal transduction also promotes neurite outgrowth and axonal regeneration in the brain $[105,112,115]$. In the brain, insulin resistance results from perturbation of insulin signal transduction, causing systemic hyperglycemia. Decreased insulin and IGF-1 have been observed in Alzheimer's disease brain [116, 117]. Also, decreased insulin receptor substrate (IRS) protein levels related to insulin resistance [118] are associated with cognitive decline in dementia [119]. Impaired insulin transduction aggravates features of Alzheimer's disease including formation of neurofibrillary tangle caused by the decreasing brain glucose level and the increase of amyloid $\beta$ aggregation
$[104,106,118,120-122]$. In addition, insulin resistance is closely linked with other metabolic symptoms, including hypertension and hyperlipidemia [123]. Adiponectin directly regulates glucose metabolism and insulin sensitivity. Adiponectin, via activation of AMPK and adiponectin, stimulates GLUT4 translocation and glucose uptake [124]. Adiponectin receptors activate AMPK, PPAR- $\alpha$, and p38 MAPK to increase insulin sensitivity $[58,125]$. An adaptor protein, APPL1, binds to adiponectin receptors that activate the AMPK and p38 MAPK pathways [126]. In addition, adiponectin decreases insulin resistance by decreasing triglyceride content in obese mice [127]. Increased tissue triglyceride content has been reported to interfere with insulin-stimulated phosphatidylinositol (PI) 3-kinase activation and subsequent GLUT 4 translocation and glucose uptake, thus leading to insulin resistance. Adipose tissue deficiency or lipodystrophy is associated with insulin resistance and metabolic dysregulation [128]. Adiponectin knockout mice show impaired insulin secretion, and intravenous adiponectin injection into $\mathrm{C} 57 \mathrm{BL} / 6$ mice induces insulin secretion $[129,130]$. AdipoR1 and 2 double knockout mice have increased triglyceride levels in the liver and exhibit insulin resistance and glucose intolerance, suggesting that AdipoR1 and AdipoR2 regulate lipid and glucose homeostasis $[14,131]$. In conclusion, adiponectin and adiponectin receptors improve insulin resistance by modulating triglyceride level and impaired insulin signal transduction. Thus, regulation of adiponectin is important impaired insulin signal transduction to improve and also adiponectin may contribute to the improvement of cognitive decline in dementia.

4.3. Adiponectin, Diabetes, and Vascular Dementia. Diabetes characterized by reduced insulin sensitivity is associated with thrombosis, myocardial infarction, and cerebrovascular disease, which can lead to infarctions and white matter ischemia [132]. Macrovascular disease causes approximately $80 \%$ of mortality in patients with T2DM. The risk of vascular diseases in patients with T2DM is decreased by lowering the blood pressure of patients with hypertension [133-135]. In addition, diabetes and hypoglycemia are associated with cognitive impairment [136-138]. Yaffe et al., in a 4-year prospective study, suggested that older women with impaired fasting glucose levels performed poorly on cognitive tests compared to those with normal glycemia [139]. Considering these associations, diabetes may be regarded as a risk factor of vascular dementia. Adiponectin levels are elevated in type I diabetics compared with healthy controls [140]. Several studies have consistently found that increased adiponectin levels are associated with reduced risk for T2DM [22, 25, 26]. Hypoadiponectinemia has been considered an underlying mechanism of insulin resistance in T2DM [141-145]. In crosssectional studies, plasma adiponectin concentrations were significantly lower in patients with diabetes [146]. In a 5year follow-up study of 1096 nondiabetics, the association between adiponectin and T2DM was attenuated after adjustment for homeostatic model assessment of insulin resistance (HOMA-IR) and was eliminated after adjustment for insulin sensitivity. These data suggest that the antidiabetic effect of 


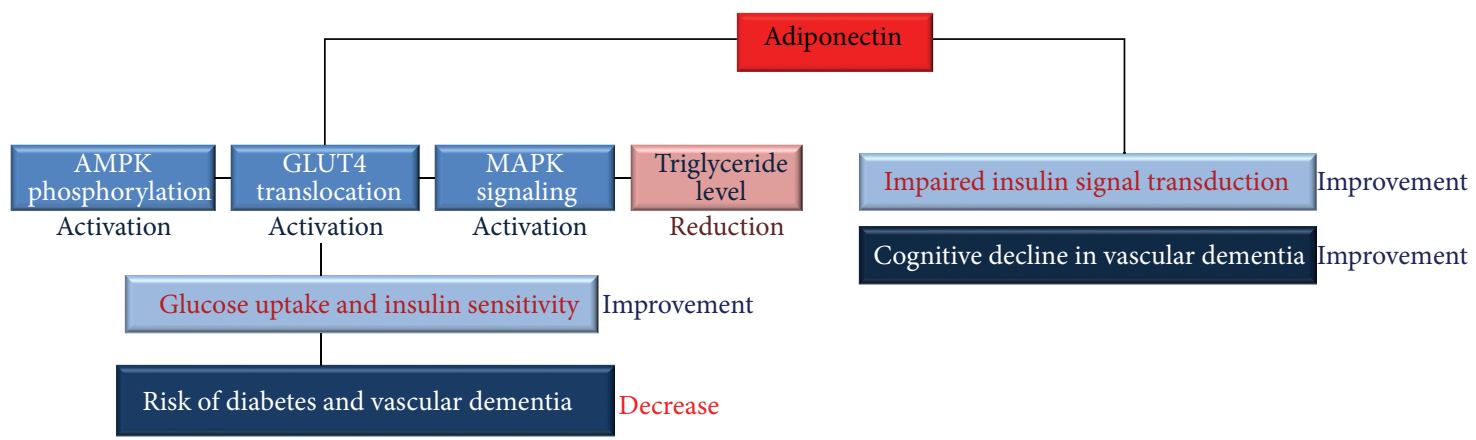

FIGURE 2: Adiponectin improves insulin sensitivity and reduces diabetes and vascular dementia risk. Adiponectin stimulates AMPK phosphorylation, GLUT4 translocation, and MAPK pathways. Adiponectin also reduces the levels of triglyceride. Consequentially, adiponectin increases glucose uptake and insulin sensitivity and reduces insulin resistance. In addition, adiponectin improves the cognitive decline by modulating impaired insulin signal transduction in vascular dementia brain. These mechanisms decrease the risk of diabetes and vascular dementia. Also, these mechanisms improve the memory dysfunction in dementia. AMPK: AMP-activated kinase, GLUT4: glucose transporter type 4, and MAPK: mitogen activated protein kinase.

adiponectin is due to insulin sensitization [147]. Adiponectin predicts against diabetes onset, and diabetic patients always show lower plasma adiponectin levels compared to the general population [148]. Thus, adiponectin reduces the risk of diabetes by regulating insulin signal transduction and insulin resistance. Suppression of adiponectin aggravates diabetes as a risk for vascular dementia. Figure 2 shows that adiponectin stimulates the phosphorylation of AMPK and GLUT4 translocation and attenuates levels of triglyceride. As a result, adiponectin enhances glucose uptake and insulin sensitivity. This indicates that adiponectin reduces the risk of diabetes and vascular dementia (Figure 2).

\section{Adiponectin, Hypertension, and Stroke}

5.1. Adiponectin and Hypertension. Hypertension has been reported as the most common risk factor for stroke worldwide and has also been gradually recognized as a risk factor for dementia [149]. Arterial hypertension contributes to the development and progression of cerebrovascular disease [150]. Hypertension exposes the cerebral microvasculature to pulsatile pressure and flow that cause vascular endothelium and smooth muscle cell tearing [151]. Many cross-sectional and longitudinal studies have demonstrated that dementia and VCI are associated with hypertension [152-156]. Therefore, previous studies suggest that hypertension is the most important risk factor for cerebral vessel dysfunction, and it contributes to cognitive decline [157, 158]. Pulse pressure (PP), a marker of arterial stiffness, has been connected with the risk of cognitive decline [159] and AD [160, 161]. Elevated pulse pressure increases the risk of cognitive decline and impaired language abilities [162]. Decreased blood pressure (BP) is a clinical manifestation of dementia in elderly subjects $[163,164]$. Endothelial nitric oxide synthase (eNOS) and nitric oxide (NO) are crucial regulators of vascular homeostasis and, in particular, endothelial function $[165,166]$. Endothelium-derived NO is a beneficial factor that promotes vasodilation and inhibits platelet aggregation, monocyte adhesion, and smooth muscle cell proliferation [167].
Adiponectin, acting via AdipoR1 and AdipoR2, promotes NO production through AMPK signaling pathway activation. AMPK activates eNOS through phosphorylation at $\mathrm{Ser}^{177}$ and facilitates complex formation between eNOS and heat shock protein 90 (HSP-90), which is required for eNOS activation [167]. Adiponectin knockout mice have reduced endothelial NO levels in vessel walls [168]. Adiponectin inhibits the inflammatory response and causes vasodilatation largely through AMPK/eNOS [169-172]. Adiponectininduced AMPK signaling promotes phosphatidylinositol 3kinase-Akt signaling, leading to angiogenic growth factor synthesis $[170,173]$. A recent study also suggests that adiponectin inhibits vascular endothelial growth factor(VEGF-) induced ROS generation and has an antioxidant role in the vasculature [174]. These actions of adiponectin are also mediated via inhibition of growth factor-stimulated extracellular signal regulated kinase (ERK) signaling. In addition, several studies indicate that adiponectin plays a role in the regulation of microvascular network flow and function $[175,176]$. Some clinical research demonstrates that plasma adiponectin levels are positively associated with arterial vasodilation [177]. Considering the role of adiponectin in vascular function, decreased adiponectin raises the risk of hypertension. Figure 3 shows that adiponectin increases AMPK phosphorylation and NO production. Platelet aggregation is decreased and vasodilation is increased due to NO production. Finally, adiponectin decreases the risk of hypertension and improves vascular cognitive impairment (Figure 3).

5.2. Adiponectin and Atherosclerosis. Atherosclerosis is a degenerative vessel disease that frequently affects large- to medium-sized arteries. In the brain, vessels of the circle of Willis are often involved [178]. Atherosclerotic plaques are prone to rupture with subsequent thrombosis $[179,180]$. The thrombus resulting from plaque rupture leads to vessel occlusion or embolizes a smaller artery [181]. Atherosclerosis plaque rupture is related to inflammation, including secretion of cytokines and matrix-metalloproteinases, 


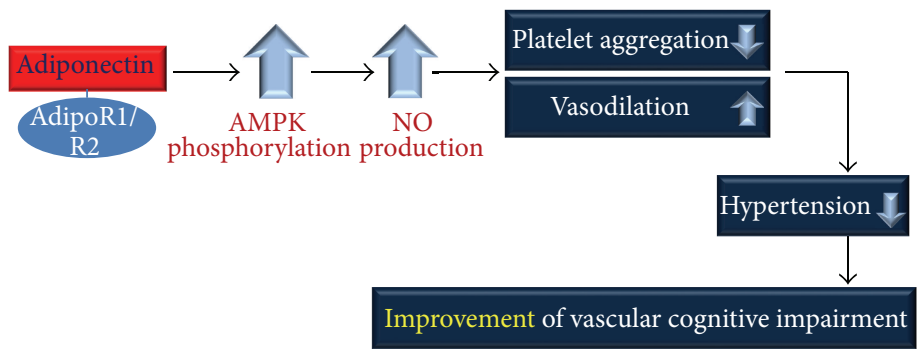

FIGURE 3: Adiponectin improves vascular cognitive impairment by stimulating NO production. Adiponectin, acting via AdipoR1 and AdipoR2, promotes AMPK phosphorylation and NO production. Increased NO reduces platelet aggregation and increases vasodilation. Consequentially, adiponectin decreases the risk of hypertension and improves vascular cognitive impairment. AMPK: AMP-activated kinase and NO: nitric oxide.

which are involved in vessel wall degradation [182-186]. Adiponectin plays the role of an antiatherogenic and antiinflammatory modulator [18]. Several studies suggest that adiponectin inhibits many peptides and cytokines related to atherosclerosis progression [187]. Adiponectin inhibits monocyte adherence to TNF- $\alpha$-stimulated endothelial cells by suppressing adhesion molecule expression [188, 189]. Adiponectin directly inhibits atherogenic molecules, such as intracellular adhesion molecule-1, vascular cellular adhesion molecule-1, and E-selectin, which are molecules associated with heightened leukocyte trafficking [189]. Adiponectin also attenuates expression of class A scavenger receptor in human macrophages and inhibits transformation of macrophages to foam cells [190]. The association between adiponectin and atherogenic factors indicates that regulation of adiponectin is important in atherosclerosis.

5.3. Adiponectin and Stroke. Several studies reported that stroke doubles the risk for dementia (poststroke dementia), and approximately $30 \%$ of stroke patients develop cognitive dysfunction within 3 years [191-194]. An association between stroke and dementia is also observed in patients younger than 50 years, and up to $50 \%$ of these patients exhibit cognitive deficits after a decade [195]. One of the first population-based studies to assess the relationship between stroke and dementia was conducted in Rochester, Minnesota [196]. Many stroke patients show gradual but continuous deterioration after a single-stroke lesion. This deterioration is characterized clinically by cognitive and behavioral dysfunction [197]. Several cross-sectional and retrospective casecontrol studies have reported an association between low adiponectin levels and increased stroke risk [16, 198-201]. In addition, adiponectin levels are associated with coronary heart disease such as coronary vascular disease [202, 203]. Several studies demonstrate that hypoadiponectinemia increases the prevalence of coronary vascular disease [189, 204]. Several studies demonstrated that adiponectin knockout $(\mathrm{APN}-\mathrm{KO})$ mice showed severe injuries during cerebral ischemia-reperfusion $[205,206]$, while adiponectin injected APN-KO mice were reduced pathological ischemia-induced damage [207]. Adiponectin blocks the interaction between the endothelial cells and leukocytes in ischemia-reperfusion and also inhibits the secondary inflammation in cerebral ischemia-reperfusion [208]. Adiponectin reduced the infarct size through nitric oxide synthase dependent mechanism in cerebral ischemic stroke mice model [209, 210]. In addition, adiponectin activates AMPK phosphorylation in cerebral ischemic stroke mice model [211]. Then, the activation of VEGF by the activated AMPK signaling promotes angiogenesis in cerebral ischemic brain $[212,213]$. Considering the results of the above studies, adiponectin is associated with the risk of stroke and reduces cerebral ischemia induced damage. This may be due to the roles of adiponectin as an antiatherogenic modulator and a vasodilator in vascular system. Figure 4 shows that adiponectin decreases the expression of atherogenic molecules and plaque formation in blood vessels. Consequentially, adiponectin attenuates the risk of stroke and vascular dementia (Figure 4).

\section{Conclusions}

Risk factors for vascular dementia include advanced age, diabetes, hypertension, atherosclerosis, and stroke. Adiponectin, an adipokine, acts as an antidiabetic and antiatherogenic regulator. Insulin sensitivity is a key cellular mechanism related to diabetes, cerebrovascular dysfunction, and cognitive decline. Adiponectin is involved in insulin sensitivity, and increased adiponectin levels improve impaired insulin signaling. Moreover, adiponectin affects the cerebrovascular function by stimulating NO production and inhibiting transformation of macrophages to foam cells. Specifically, we summarize the findings as follows.

(1) Vascular dementia characterized by cognitive decline is associated with increased age because insulin receptors, which are related to cognitive function, decrease with age. Adiponectin is associated with age-related diseases, including cardiovascular disease and metabolic disease. Adiponectin is mediated via the activation of AMPK, and adiponectin stimulates GLUT4 translocation and glucose uptake. Moreover, binding between adiponectin and adiponectin receptors activates AMPK, PPAR- $\alpha$, and p38 MAPK to increase insulin sensitivity. In addition, in clinical studies, an association between decreased adiponectin and diabetes was demonstrated. In conclusion, adiponectin improves impaired insulin signaling and improves cognitive decline as a typical feature of vascular dementia. 


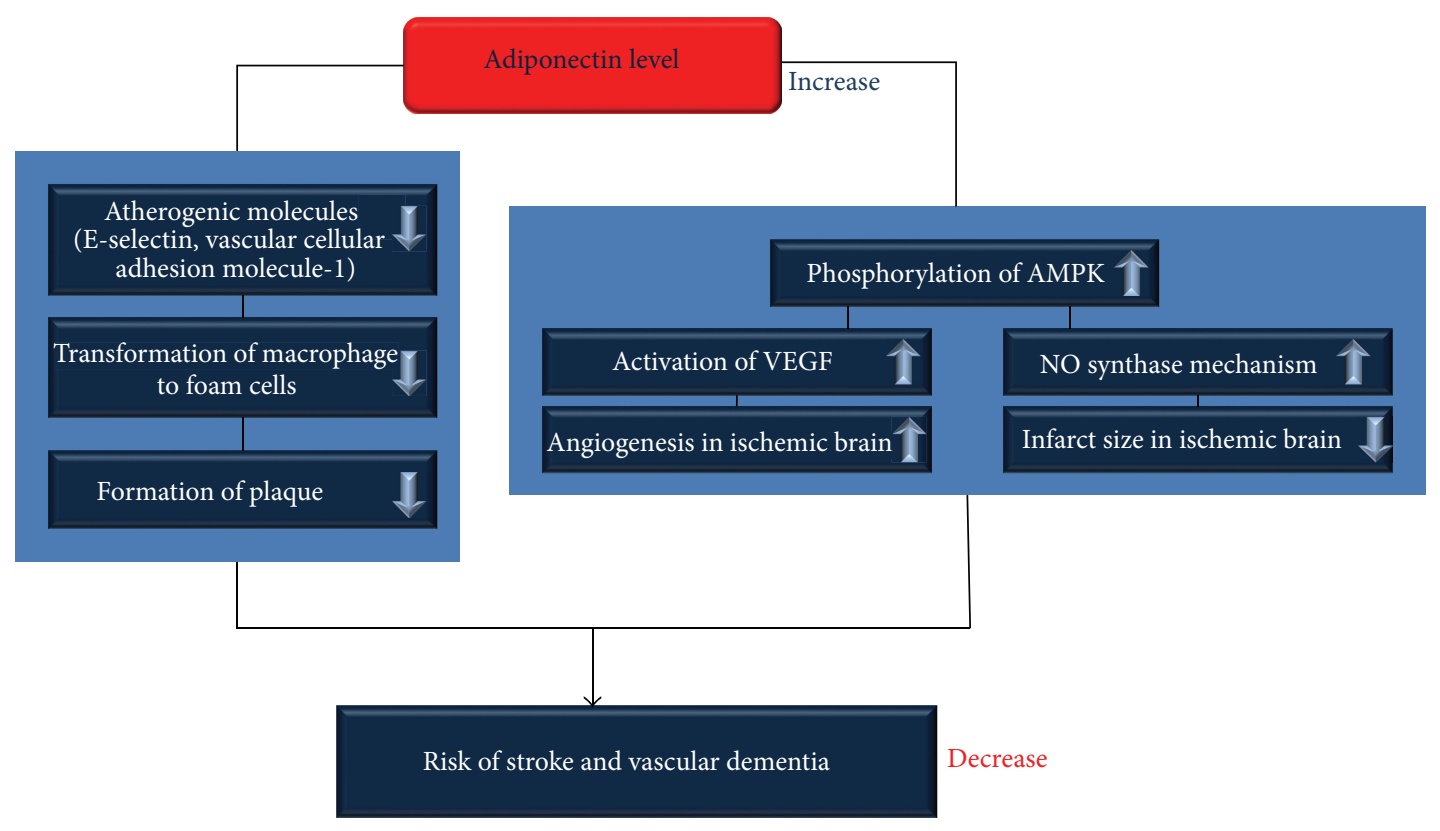

FIGURE 4: Adiponectin attenuates the risk of stroke and vascular dementia. Adiponectin decreases the expression of atherogenic molecules and formation of form cells in blood vessels. Adiponectin attenuates the risk of stroke by decreasing plaque formation in blood vessels. In addition, adiponectin binds with AdipoR1 and AdipoR2 and then activates the phosphorylation of AMPK. Increased AMPK phosphorylation promotes the activation of VEGF and NO synthase mechanism. As a result, adiponectin ameliorates angiogenesis in ischemic brain and reduces infarct size in ischemic brain. Consequentially, adiponectin decreases the risk of stroke and vascular dementia. AMPK: AMP-activated kinase, VEGF: vascular endothelial growth factor, and NO: nitric oxide.

(2) Vascular dementia characterized by cerebrovascular dysfunction is associated with hypertension, atherosclerosis, and stroke. Adiponectin stimulates NO production through the AMPK signaling pathway. Adiponectin also plays the role of an antiatherogenic modulator. Adiponectin inhibits atherogenic molecules and attenuates the transformation of macrophages to foam cells. In conclusion, adiponectin improves vascular dysfunction and alleviates the progression of hypertension, atherosclerosis, and stroke as risk factors for vascular dementia.

(3) Taken together, adiponectin attenuates the risk of vascular dementia and ameliorates vascular dementiarelated pathologies including cerebrovascular dysfunction and cognitive decline which resulted from impaired insulin transduction and neuroinflammation.

In this review, we summarized the current research regarding the association between risk factors for vascular dementia and adiponectin. Considering the relationship between adiponectin and risk factors for vascular dementia including aging, diabetes, hypertension, atherosclerosis, and stroke, we suggest that further studies are necessary to examine the role of adiponectin in vascular dementia. Moreover, we emphasize that the regulation of adiponectin levels and receptors of adiponectin would be important for the prevention and treatment of vascular dementia.

\section{Conflict of Interests}

The authors declare no conflict of interests.

\section{Acknowledgments}

This work was supported by the National Research Foundation of Korea (NRF) Grant funded by the Korean government (MEST) (2012-0005440). This work was also supported by the Brain Korea 21 Plus Project for Medical Science, Yonsei University.

\section{References}

[1] A. Ruitenberg, A. Ott, J. C. van Swieten, A. Hofman, and M. M. B. Breteler, "Incidence of dementia: does gender make a difference?” Neurobiology of Aging, vol. 22, no. 4, pp. 575-580, 2001.

[2] P. B. Gorelick, A. Scuteri, S. E. Black et al., "Vascular contributions to cognitive impairment and dementia: a statement for healthcare professionals from the American Heart Association/American Stroke Association," Stroke, vol. 42, no. 9, pp. 2672-2713, 2011.

[3] M. Wortmann, "Dementia: a global health priority-highlights from an ADI and World Health Organization report," Alzheimer's Research \& Therapy, vol. 4, no. 5, article 40, 2012.

[4] Alzheimer's Association, "2012 Alzheimer's disease facts and figures," Alzheimer's \& Dementia, vol. 8, no. 2, pp. 131-168, 2012.

[5] S. Craft, "The role of metabolic disorders in Alzheimer disease and vascular dementia: two roads converged," Archives of Neurology, vol. 66, no. 3, pp. 300-305, 2009. 
[6] H. Fillit, D. T. Nash, T. Rundek, and A. Zuckerman, "Cardiovascular risk factors and dementia," The American Journal of Geriatric Pharmacotherapy, vol. 6, no. 2, pp. 100-118, 2008.

[7] K. Honjo, S. E. Black, and N. P. Verhoeff, "Alzheimer's disease, cerebrovascular disease, and the $\beta$-amyloid cascade," The Canadian Journal of Neurological Sciences, vol. 39, no. 6, pp. 712-728, 2012.

[8] C. Purnell, S. Gao, C. M. Callahan, and H. C. Hendrie, "Cardiovascular risk factors and incident alzheimer disease: a systematic review of the literature," Alzheimer Disease and Associated Disorders, vol. 23, no. 1, pp. 1-10, 2009.

[9] J. A. Schneider, Z. Arvanitakis, W. Bang, and D. A. Bennett, "Mixed brain pathologies account for most dementia cases in community-dwelling older persons," Neurology, vol. 69, no. 24, pp. 2197-2204, 2007.

[10] J. B. Toledo, S. E. Arnold, K. Raible et al., "Contribution of cerebrovascular disease in autopsy confirmed neurodegenerative disease cases in the National Alzheimer's Coordinating Centre," Brain, vol. 136, no. 9, pp. 2697-2706, 2013.

[11] G. C. Roman, T. K. Tatemichi, T. Erkinjuntti et al., "Vascular dementia: diagnostic criteria for research studies: report of the NINDS-AIREN International Workshop," Neurology, vol. 43, no. 2, pp. 250-260, 1993.

[12] V. C. Hachinski, J. V. Bowler, C. Loeb, G. C. Roman, and T. K. Tatemichi, "Vascular dementia," Neurology, vol. 43, no. 10, pp. 2159-2161, 1993.

[13] UK Prospective Diabetes Study (UKPDS) Group, "Intensive blood-glucose control with sulphonylureas or insulin compared with conventional treatment and risk of complications in patients with type 2 diabetes (UKPDS 33)," The Lancet, vol. 352, no. 9131, pp. 837-853, 1998.

[14] T. Kadowaki, T. Yamauchi, N. Kubota, K. Hara, K. Ueki, and $\mathrm{K}$. Tobe, "Adiponectin and adiponectin receptors in insulin resistance, diabetes, and the metabolic syndrome," The Journal of Clinical Investigation, vol. 116, no. 7, pp. 1784-1792, 2006.

[15] M. Shimabukuro, N. Higa, T. Asahi et al., "Hypoadiponectinemia is closely linked to endothelial dysfunction in man," The Journal of Clinical Endocrinology \& Metabolism, vol. 88, no. 7, pp. 3236-3240, 2003.

[16] M. P. Chen, J. C. Tsai, F. M. Chung et al., "Hypoadiponectinemia is associated with ischemic cerebrovascular disease," Arteriosclerosis, Thrombosis, and Vascular Biology, vol. 25, no. 4, pp. 821-826, 2005.

[17] M. B. Snijder, R. J. Heine, J. C. Seidell et al., "Associations of adiponectin levels with incident impaired glucose metabolism and type 2 diabetes in older men and women the hoorn study," Diabetes Care, vol. 29, no. 11, pp. 2498-2503, 2006.

[18] P.-A. Jansson, F. Pellmé, A. Hammarstedt et al., "A novel cellular marker of insulin resistance and early atherosclerosis in humans is related to impaired fat cell differentiation and low adiponectin," The FASEB Journal, vol. 17, no. 11, pp. 1434-1440, 2003.

[19] K. Dunajska, A. Milewicz, D. Jędrzejuk et al., "Plasma adiponectin concentration in relation to severity of coronary atherosclerosis and cardiovascular risk factors in middle-aged men," Endocrine, vol. 25, no. 3, pp. 215-221, 2004.

[20] T. Shoji, H. Koyama, S. Fukumoto et al., "Platelet activation is associated with hypoadiponectinemia and carotid atherosclerosis," Atherosclerosis, vol. 188, no. 1, pp. 190-195, 2006.

[21] J. Saltevo, M. Laakso, J. Jokelainen, S. Keinänen-Kiukaanniemi, E. Kumpusalo, and M. Vanhala, "Levels of adiponectin, Creactive protein and interleukin-1 receptor antagonist are associated with insulin sensitivity: a population-based study," Diabetes/Metabolism Research and Reviews, vol. 24, no. 5, pp. 378-383, 2008.

[22] S. G. Wannamethee, G. D. O. Lowe, A. Rumley, L. Cherry, P. H. Whincup, and N. Sattar, "Adipokines and risk of type 2 diabetes in older men," Diabetes Care, vol. 30, no. 5, pp. 1200-1205, 2007.

[23] C. Heidemann, Q. Sun, R. M. van Dam et al., “Total and highmolecular-weight adiponectin and resistin in relation to the risk for type 2 diabetes in women," Annals of Internal Medicine, vol. 149, no. 5, pp. 307-316, 2008.

[24] S. H. Ley, S. B. Harris, P. W. Connelly et al., "Adipokines and incident type 2 diabetes in a Canadian Aborigine population: the Sandy Lake Health and Diabetes Project," Diabetes Care, vol. 31, no. 7, pp. 1410-1415, 2008.

[25] A. G. Tabák, E. J. Brunner, M. A. Miller et al., "Low serum adiponectin predicts 10 -year risk of type 2 diabetes and hbalc independently of obesity, lipids, and inflammation: Whitehall II study," Hormone and Metabolic Research, vol. 41, no. 8, pp. 626-629, 2009.

[26] W. Koenig, N. Khuseyinova, J. Baumert, C. Meisinger, and H. Löwel, "Serum concentrations of adiponectin and risk of type 2 diabetes mellitus and coronary heart disease in apparently healthy middle-aged men: results from the 18-year follow-up of a large cohort from southern Germany," Journal of the American College of Cardiology, vol. 48, no. 7, pp. 1369-1377, 2006.

[27] D. R. Thal, L. T. Grinberg, and J. Attems, "Vascular dementia: different forms of vessel disorders contribute to the development of dementia in the elderly brain," Experimental Gerontology, vol. 47, no. 11, pp. 816-824, 2012.

[28] R. A. Cohen and X. Tong, "Vascular oxidative stress: the common link in hypertensive and diabetic vascular disease," Journal of Cardiovascular Pharmacology, vol. 55, no. 4, pp. 308316, 2010.

[29] C. Iadecola and R. L. Davisson, "Hypertension and cerebrovascular dysfunction," Cell Metabolism, vol. 7, no. 6, pp. 476-484, 2008.

[30] K. F. Yates, V. Sweat, P. L. Yau, M. M. Turchiano, and A. Convit, "Impact of metabolic syndrome on cognition and brain: a selected review of the literature," Arteriosclerosis, Thrombosis, and Vascular Biology, vol. 32, no. 9, pp. 2060-2067, 2012.

[31] F. M. Faraci, "Protecting against vascular disease in brain," American Journal of Physiology: Heart and Circulatory Physiology, vol. 300, no. 5, pp. H1566-H1582, 2011.

[32] R. Sahathevan, A. Brodtmann, and G. A. Donnan, "Dementia, stroke, and vascular risk factors; a review," International Journal of Stroke, vol. 7, no. 1, pp. 61-73, 2012.

[33] M. M. Corrada, R. Brookmeyer, D. Berlau, A. Paganini-Hill, and C. H. Kawas, "Prevalence of dementia after age 90: results from the 90+ study," Neurology, vol. 71, no. 5, pp. 337-343, 2008.

[34] J. A. H. R. Claassen, R. Diaz-Arrastia, K. Martin-Cook, B. D. Levine, and R. Zhang, "Altered cerebral hemodynamics in early alzheimer disease: a pilot study using transcranial doppler," Journal of Alzheimer's Disease, vol. 17, no. 3, pp. 621-629, 2009.

[35] Y. Z. Gao, J. J. Zhang, H. Liu, G. Y. Wu, L. Xiong, and M. Shu, "Regional cerebral blood flow and cerebrovascular reactivity in Alzheimer's disease and vascular dementia assessed by arterial spinlabeling magnetic resonance imaging," Current Neurovascular Research, vol. 10, no. 1, pp. 49-53, 2013.

[36] C. Luckhaus, M. O. Flüß, H.-J. Wittsack et al., "Detection of changed regional cerebral blood flow in mild cognitive 
impairment and early Alzheimer's dementia by perfusionweighted magnetic resonance imaging," NeuroImage, vol. 40, no. 2, pp. 495-503, 2008.

[37] M. J. Mentis, B. Horwitz, C. L. Grady et al., "Visual cortical dysfunction in Alzheimer's disease evaluated with a temporally graded "stress test" during PET," American Journal of Psychiatry, vol. 153, no. 1, pp. 32-40, 1996.

[38] E. Niedermeyer, "Alzheimer disease: caused by primary deficiency of the cerebral blood flow," Clinical EEG and Neuroscience, vol. 37, no. 3, pp. 175-177, 2006.

[39] A. Ruitenberg, T. den Heijer, S. L. M. Bakker et al., "Cerebral hypoperfusion and clinical onset of dementia: the Rotterdam study," Annals of Neurology, vol. 57, no. 6, pp. 789-794, 2005.

[40] B. Sabayan, S. Jansen, A. M. Oleksik et al., "Cerebrovascular hemodynamics in Alzheimer's disease and vascular dementia: a meta-analysis of transcranial Doppler studies," Ageing Research Reviews, vol. 11, no. 2, pp. 271-277, 2012.

[41] M. Tanaka, H. Fukuyama, H. Yamauchi et al., "Regional cerebral blood flow abnormalities in nondemented patients with memory impairment," Journal of Neuroimaging, vol. 12, no. 2, pp. 112118, 2002.

[42] C. Iadecola, "Neurovascular regulation in the normal brain and in Alzheimer's disease," Nature Reviews Neuroscience, vol. 5, no. 5, pp. 347-360, 2004.

[43] F. I. Achike, N.-H. P. To, H. Wang, and C.-Y. Kwan, “Obesity, metabolic syndrome, adipocytes and vascular function: a holistic viewpoint," Clinical and Experimental Pharmacology and Physiology, vol. 38, no. 1, pp. 1-10, 2011.

[44] Y. Okamoto, S. Kihara, T. Funahashi, Y. Matsuzawa, and P. Libby, "Adiponectin: a key adipocytokine in metabolic syndrome," Clinical Science, vol. 110, no. 3, pp. 267-278, 2006.

[45] P. E. Scherer, S. Williams, M. Fogliano, G. Baldini, and H. F. Lodish, "A novel serum protein similar to Clq, produced exclusively in adipocytes," The Journal of Biological Chemistry, vol. 270, no. 45, pp. 26746-26749, 1995.

[46] L. Shapiro and P. E. Scherer, "The crystal structure of a complement-1q family protein suggests an evolutionary link to tumor necrosis factor," Current Biology, vol. 8, no. 6, pp. 335$338,1998$.

[47] H. Ruan and H. F. Lodish, "Insulin resistance in adipose tissue: direct and indirect effects of tumor necrosis factor- $\alpha$," Cytokine and Growth Factor Reviews, vol. 14, no. 5, pp. 447-455, 2003.

[48] A. H. Kissebah, G. E. Sonnenberg, J. Myklebust et al., "Quantitative trait loci on chromosomes 3 and 17 influence phenotypes of the metabolic syndrome," Proceedings of the National Academy of Sciences of the United States of America, vol. 97, no. 26, pp. 14478-14483, 2000.

[49] Y. Mori, S. Otabe, C. Dina et al., "Genome-wide search for type 2 diabetes in Japanese affected sib-pairs confirms susceptibility genes on $3 q, 15 q$, and $20 q$ and identifies two new candidate loci on 7p and 1lp," Diabetes, vol. 51, no. 4, pp. 1247-1255, 2002.

[50] F. Vasseur, N. Helbecque, C. Dina et al., "Single-nucleotide polymorphism haplotypes in the both proximal promoter and exon 3 of the APM1 gene modulate adipocyte-secreted adiponectin hormone levels and contribute to the genetic risk for type 2 diabetes in French Caucasians," Human Molecular Genetics, vol. 11, no. 21, pp. 2607-2614, 2002.

[51] H.-B. Leu, C.-M. Chung, S.-J. Lin, Y.-S. Jong, W.-H. Pan, and J.W. Chen, "Adiponectin gene polymorphism is selectively associated with the concomitant presence of metabolic syndrome and essential hypertension," PLoS ONE, vol. 6, no. 5, Article ID e19999, 2011.
[52] M. Stumvoll, O. Tschritter, A. Fritsche et al., "Association of the T-G polymorphism in adiponectin (exon 2) with obesity and insulin sensitivity: interaction with family history of type 2 diabetes," Diabetes, vol. 51, no. 1, pp. 37-41, 2002.

[53] A. Kollias, P. C. Tsiotra, I. Ikonomidis et al., "Adiponectin levels and expression of adiponectin receptors in isolated monocytes from overweight patients with coronary artery disease," Cardiovascular Diabetology, vol. 10, article 14, 2011.

[54] K. Hara, P. Boutin, Y. Mori et al., "Genetic variation in the gene encoding adiponectin is associated with an increased risk of type 2 diabetes in the Japanese population," Diabetes, vol. 51, no. 2, pp. 536-540, 2002.

[55] V. J. Bermudez, E. Rojas, A. Toledo et al., "Single-nucleotide polymorphisms in adiponectin, AdipoR1, and AdipoR2 genes: insulin resistance and type 2 diabetes mellitus candidate genes," American Journal of Therapeutics, vol. 20, no. 4, pp. 414-421, 2013.

[56] C. Menzaghi, T. Ercolino, R. D. Paola et al., "A haplotype at the adiponectin locus is associated with obesity and other features of the insulin resistance syndrome," Diabetes, vol. 51, no. 7, pp. 2306-2312, 2002.

[57] Z. Zhang, H. Tian, Y. Zhao et al., "Meta-analysis of the association between adiponectin gene $+276 \mathrm{~g} / \mathrm{T}$ polymorphisms and coronary atherosclerotic heart disease," Wei Sheng Yan Jiu, vol. 42, no. 4, pp. 693-697, 2013.

[58] T. Yamauchi, J. Kamon, H. Waki et al., "Globular adiponectin protected ob/ob mice from diabetes and ApoE-deficient mice from atherosclerosis," The Journal of Biological Chemistry, vol. 278, no. 4, pp. 2461-2468, 2003.

[59] F. Ziemke and C. S. Mantzoros, "Adiponectin in insulin resistance: lessons from translational research," The American Journal of Clinical Nutrition, vol. 91, no. 1, pp. 258S-261S, 2010.

[60] J. Spranger, S. Verma, I. Göhring et al., "Adiponectin does not cross the blood-brain barrier but modifies cytokine expression of brain endothelial cells," Diabetes, vol. 55, no. 1, pp. 141-147, 2006.

[61] N. Kubota, W. Yano, T. Kubota et al., "Adiponectin stimulates AMP-activated protein kinase in the hypothalamus and increases food intake," Cell Metabolism, vol. 6, no. 1, pp. 55-68, 2007.

[62] A. Psilopanagioti, H. Papadaki, E. F. Kranioti, T. K. Alexandrides, and J. N. Varakis, "Expression of adiponectin and adiponectin receptors in human pituitary gland and brain," Neuroendocrinology, vol. 89, no. 1, pp. 38-47, 2009.

[63] E. Zoico, V. di Francesco, G. Mazzali et al., "Adipocytokines, fat distribution, and insulin resistance in elderly men and women," The Journals of Gerontology A: Biological Sciences and Medical Sciences, vol. 59, no. 9, pp. 935-939, 2004.

[64] M. Cnop, P. J. Havel, K. M. Utzschneider et al., "Relationship of adiponectin to body fat distribution, insulin sensitivity and plasma lipoproteins: evidence for independent roles of age and sex," Diabetologia, vol. 46, no. 4, pp. 459-469, 2003.

[65] A. M. Kanaya, T. Harris, B. H. Goodpaster, F. Tylavsky, and S. R. Cummings, "Adipocytokines attenuate the association between visceral adiposity and diabetes in older adults," Diabetes Care, vol. 27, no. 6, pp. 1375-1380, 2004.

[66] S. Ahmadizad, A. H. Haghighi, and M. R. Hamedinia, "Effects of resistance versus endurance training on serum adiponectin and insulin resistance index," European Journal of Endocrinology, vol. 157, no. 5, pp. 625-631, 2007.

[67] M. Blüher, C. J. Williams, N. Klöting et al., "Gene expression of adiponectin receptors in human visceral and subcutaneous 
adipose tissue is related to insulin resistance and metabolic parameters and is altered in response to physical training," Diabetes Care, vol. 30, no. 12, pp. 3110-3115, 2007.

[68] M. Blüher, J. W. Bullen Jr., J. H. Lee et al., "Circulating adiponectin and expression of adiponectin receptors in human skeletal muscle: associations with metabolic parameters and insulin resistance and regulation by physical training," The Journal of Clinical Endocrinology \& Metabolism, vol. 91, no. 6, pp. 2310-2316, 2006.

[69] H. Tilg and A. R. Moschen, "Adipocytokines: mediators linking adipose tissue, inflammation and immunity," Nature Reviews Immunology, vol. 6, no. 10, pp. 772-783, 2006.

[70] P. M. Ridker, J. E. Buring, N. R. Cook, and N. Rifai, "Creactive protein, the metabolic syndrome, and risk of incident cardiovascular events: an 8-year follow-up of 14719 initially healthy American women," Circulation, vol. 107, no. 3, pp. 391397, 2003.

[71] U. B. Pajvani and P. E. Scherer, "Adiponectin: systemic contributor to insulin sensitivity," Current Diabetes Reports, vol. 3, no. 3, pp. 207-213, 2003.

[72] S. Lim, H. C. Sung, I.-K. Jeong et al., "Insulin-sensitizing effects of exercise on adiponectin and retinol-binding protein-4 concentrations in young and middle-aged women," The Journal of Clinical Endocrinology \& Metabolism, vol. 93, no. 6, pp. 22632268, 2008

[73] T. Yamauchi, J. Kamon, Y. Minokoshi et al., "Adiponectin stimulates glucose utilization and fatty-acid oxidation by activating AMP-activated protein kinase," Nature Medicine, vol. 8, no. 11, pp. 1288-1295, 2002.

[74] N. Stefan, B. Vozarova, T. Funahashi et al., "Plasma adiponectin concentration is associated with skeletal muscle insulin receptor tyrosine phosphorylation, and low plasma concentration precedes a decrease in whole-body insulin sensitivity in humans," Diabetes, vol. 51, no. 6, pp. 1884-1888, 2002.

[75] A. S. Lihn, S. B. Pedersen, and B. Richelsen, "Adiponectin: action, regulation and association to insulin sensitivity," Obesity Reviews, vol. 6, no. 1, pp. 13-21, 2005.

[76] B. Iglseder, V. Mackevics, A. Stadlmayer, G. Tasch, G. Ladurner, and B. Paulweber, "Plasma adiponectin levels and sonographic phenotypes of subclinical carotid artery atherosclerosis: data from the SAPHIR study," Stroke, vol. 36, no. 12, pp. 2577-2582, 2005.

[77] W.-Q. Wang, H.-F. Zhang, G.-X. Gao, Q.-X. Bai, R. Li, and X.-M. Wang, "Adiponectin inhibits hyperlipidemia-induced platelet aggregation via attenuating oxidative/nitrative stress," Physiological Research, vol. 60, no. 2, pp. 347-354, 2011.

[78] P. Restituto, I. Colina, J. J. Varo, and N. Varo, "Adiponectin diminishes platelet aggregation and sCD40L release. Potential role in the metabolic syndrome," American Journal of Physiology: Endocrinology and Metabolism, vol. 298, no. 5, pp. E1072E1077, 2010.

[79] M. Prince, R. Bryce, E. Albanese, A. Wimo, W. Ribeiro, and C. P. Ferri, "The global prevalence of dementia: a systematic review and metaanalysis," Alzheimer's \& Dementia, vol. 9, no. 1, pp. 63.e2-75.e2, 2013.

[80] G. J. Brewer, "Epigenetic oxidative redox shift (EORS) theory of aging unifies the free radical and insulin signaling theories," Experimental Gerontology, vol. 45, no. 3, pp. 173-179, 2010.

[81] A. I. Duarte, P. I. Moreira, and C. R. Oliveira, "Insulin in central nervous system: more than just a peripheral hormone," Journal of Aging Research, vol. 2012, Article ID 384017, 21 pages, 2012.
[82] L. Kappeler, C. D. M. Filho, J. Dupont et al., "Brain IGF1 receptors control mammalian growth and lifespan through a neuroendocrine mechanism," PLoS Biology, vol. 6, no. 10, Article ID e254, 2008.

[83] C. Franceschi, F. Olivieri, F. Marchegiani et al., "Genes involved in immune response/inflammation, IGF1/insulin pathway and response to oxidative stress play a major role in the genetics of human longevity: the lesson of centenarians," Mechanisms of Ageing and Development, vol. 126, no. 2, pp. 351-361, 2005.

[84] A. Lorenzini, A. B. Salmon, C. Lerner et al., "Mice producing reduced levels of insulin-like growth factor type 1 display an increase in maximum, but not mean, life span," The Journals of Gerontology A: Biological Sciences and Medical Sciences, vol. 69, no. 4, pp. 410-419, 2014.

[85] C. Selman, S. Lingard, A. I. Choudhury et al., "Evidence for lifespan extension and delayed age-related biomarkers in insulin receptor substrate 1 null mice," The FASEB Journal, vol. 22, no. 3, pp. 807-818, 2008.

[86] M. Blüher, B. B. Kahn, and C. R. Kahn, "Extended longevity in mice lacking the insulin receptor in adipose tissue," Science, vol. 299, no. 5606, pp. 572-574, 2003.

[87] M. Holzenberger, J. Dupont, B. Ducos et al., "IGF-1 receptor regulates lifespan and resistance to oxidative stress in mice," Nature, vol. 421, no. 6919, pp. 182-187, 2003.

[88] A. Besson, S. Salemi, S. Gallati et al., "Reduced longevity in untreated patients with isolated growth hormone deficiency," The Journal of Clinical Endocrinology \& Metabolism, vol. 88, no. 8, pp. 3664-3667, 2003.

[89] E. S. Ford, W. H. Giles, and W. H. Dietz, "Prevalence of the metabolic syndrome among US adults: findings from the Third National Health and Nutrition Examination Survey," The Journal of the American Medical Association, vol. 287, no. 3, pp. 356-359, 2002.

[90] J. Kobayashi, K. Nishimura, M. Matoba, N. Maekawa, and H. Mabuchi, "Generation and gender differences in the components contributing to the diagnosis of the metabolic syndrome according to the Japanese criteria," Circulation Journal, vol. 71, no. 11, pp. 1734-1737, 2007.

[91] T. Fulop, A. Larbi, and N. Douziech, "Insulin receptor and ageing," Pathologie Biologie, vol. 51, no. 10, pp. 574-580, 2003.

[92] A. P. Muller, A. M. Fernandez, C. Haas, E. Zimmer, L. V. Portela, and I. Torres-Aleman, "Reduced brain insulin-like growth factor I function during aging," Molecular and Cellular Neuroscience, vol. 49, no. 1, pp. 9-12, 2012.

[93] J.-A. Kim, Y. Wei, and J. R. Sowers, "Role of mitochondrial dysfunction in insulin resistance," Circulation Research, vol. 102, no. 4, pp. 401-414, 2008.

[94] M. A. Abdul-Ghani and R. A. DeFronzo, "Mitochondrial dysfunction, insulin resistance, and type 2 diabetes mellitus," Current Diabetes Reports, vol. 8, no. 3, pp. 173-178, 2008.

[95] K. F. Petersen, D. Befroy, S. Dufour et al., "Mitochondrial dysfunction in the elderly: possible role in insulin resistance," Science, vol. 300, no. 5622, pp. 1140-1142, 2003.

[96] R. Barazzoni, K. R. Short, and K. S. Nair, "Effects of aging on mitochondrial DNA copy number and cytochrome $c$ oxidase gene expression in rat skeletal muscle, liver, and heart," The Journal of Biological Chemistry, vol. 275, no. 5, pp. 3343-3347, 2000.

[97] G. A. Cortopassi, D. Shibata, N.-W. Soong, and N. Arnheim, "A pattern of accumulation of a somatic deletion of mitochondrial DNA in aging human tissues," Proceedings of the National 
Academy of Sciences of the United States of America, vol. 89, no. 16, pp. 7370-7374, 1992.

[98] C. A. Benbassat, K. C. Maki, and T. G. Unterman, "Circulating levels of insulin-like growth factor (IGF) binding protein-1 and -3 in aging men: relationships to insulin, glucose, IGF, and dehydroepiandrosterone sulfate levels and anthropometric measures," The Journal of Clinical Endocrinology \& Metabolism, vol. 82, no. 5, pp. 1484-1491, 1997.

[99] E. Corpas, S. M. Harman, and M. R. Blackman, "Human growth hormone and human aging," Endocrine Reviews, vol. 14, no. 1, pp. 20-39, 1993.

[100] D. Rudman, A. G. Feller, H. S. Nagraj et al., "Effects of human growth hormone in men over 60 years old," The New England Journal of Medicine, vol. 323, no. 1, pp. 1-6, 1990.

[101] N. E. Gulcelik, M. Halil, S. Ariogul, and A. Usman, "Adipocytokines and aging: adiponectin and leptin," Minerva Endocrinologica, vol. 38, no. 2, pp. 203-210, 2013.

[102] T. Minamino, M. Orimo, I. Shimizu et al., "A crucial role for adipose tissue p53 in the regulation of insulin resistance," Nature Medicine, vol. 15, no. 9, pp. 1082-1087, 2009.

[103] R. J. Schulingkamp, T. C. Pagano, D. Hung, and R. B. Raffa, "Insulin receptors and insulin action in the brain: review and clinical implications," Neuroscience and Biobehavioral Reviews, vol. 24, no. 8, pp. 855-872, 2000.

[104] L. P. van der Heide, G. M. J. Ramakers, and M. P. Smidt, "Insulin signaling in the central nervous system: learning to survive," Progress in Neurobiology, vol. 79, no. 4, pp. 205-221, 2006.

[105] A. R. Cole, A. Astell, C. Green, and C. Sutherland, "Molecular connexions between dementia and diabetes," Neuroscience and Biobehavioral Reviews, vol. 31, no. 7, pp. 1046-1063, 2007.

[106] L. Plum, M. Schubert, and J. C. Brüning, "The role of insulin receptor signaling in the brain," Trends in Endocrinology and Metabolism, vol. 16, no. 2, pp. 59-65, 2005.

[107] L. Gasparini, W. J. Netzer, P. Greengard, and H. Xu, "Does insulin dysfunction play a role in Alzheimer's disease?" Trends in Pharmacological Sciences, vol. 23, no. 6, pp. 288-293, 2002.

[108] D. Bosco, A. Fava, M. Plastino, T. Montalcini, and A. Pujia, "Possible implications of insulin resistance and glucose metabolism in Alzheimer's disease pathogenesis," Journal of Cellular and Molecular Medicine, vol. 15, no. 9, pp. 1807-1821, 2011.

[109] X. Fang, S. X. Yu, Y. Lu, R. C. Bast Jr., J. R. Woodgett, and G. B. Mills, "Phosphorylation and inactivation of glycogen synthase kinase 3 by protein kinase A," Proceedings of the National Academy of Sciences of the United States of America, vol. 97, no. 22, pp. 11960-11965, 2000.

[110] B. Kim and E. L. Feldman, "Insulin resistance in the nervous system," Trends in Endocrinology and Metabolism, vol. 23, no. 3, pp. 133-141, 2012.

[111] S. Cunnane, S. Nugent, M. Roy et al., "Brain fuel metabolism, aging, and Alzheimer's disease," Nutrition, vol. 27, no. 1, pp. 320, 2011.

[112] E. C. McNay and A. K. Recknagel, "Brain insulin signaling: a key component of cognitive processes and a potential basis for cognitive impairment in type 2 diabetes," Neurobiology of Learning and Memory, vol. 96, no. 3, pp. 432-442, 2011.

[113] Y. T. Wang and M. W. Salter, "Regulation of NMDA receptors by tyrosine kinases and phosphatases," Nature, vol. 369, no. 6477, pp. 233-235, 1994.
[114] L. P. van der Heide, A. Kamal, A. Artola, W. H. Gispen, and G. M. J. Ramakers, "Insulin modulates hippocampal activitydependent synaptic plasticity in a $N$-methyl-D-aspartate receptor and phosphatidyl-inositol-3-kinase-dependent manner," Journal of Neurochemistry, vol. 94, no. 4, pp. 1158-1166, 2005.

[115] S. C. Correia, R. X. Santos, G. Perry, X. Zhu, P. IMoreira, and M. A. Smith, "Insulin-resistant brain state: the culprit in sporadic Alzheimer's disease?” Ageing Research Reviews, vol. 10, no. 2, pp. 264-273, 2011.

[116] E. Steen, B. M. Terry, E. J. Rivera et al., "Impaired insulin and insulin-like growth factor expression and signaling mechanisms in Alzheimer's disease-is this type 3 diabetes?" Journal of Alzheimer's Disease, vol. 7, no. 1, pp. 63-80, 2005.

[117] E. J. Rivera, A. Goldin, N. Fulmer, R. Tavares, J. R. Wands, and S. M. de la Monte, "Insulin and insulin-like growth factor expression and function deteriorate with progression of Alzheimer's disease: link to brain reductions in acetylcholine," Journal of Alzheimer's Disease, vol. 8, no. 3, pp. 247-268, 2005.

[118] S. Craft, S. Asthana, J. W. Newcomer et al., "Enhancement of memory in Alzheimer disease with insulin and somatostatin, but not glucose," Archives of General Psychiatry, vol. 56, no. 12, pp. 1135-1140, 1999.

[119] V. Vingtdeux, P. Davies, D. W. Dickson, and P. Marambaud, "AMPK is abnormally activated in tangle-and pre-tanglebearing neurons in Alzheimer's disease and other tauopathies," Acta Neuropathologica, vol. 121, no. 3, pp. 337-349, 2011.

[120] C. R. Park, R. J. Seeley, S. Craft, and S. C. Woods, "Intracerebroventricular insulin enhances memory in a passive-avoidance task," Physiology and Behavior, vol. 68, no. 4, pp. 509-514, 2000.

[121] S. Craft, S. Asthana, G. Schellenberg et al., "Insulin metabolism in Alzheimer's disease differs according to apolipoprotein $\mathrm{E}$ genotype and gender," Neuroendocrinology, vol. 70, no. 2, pp. 146-152, 1999.

[122] M. A. Reger, G. S. Watson, P. S. Green et al., "Intranasal insulin improves cognition and modulates $\beta$-amyloid in early $\mathrm{AD}$," Neurology, vol. 70, no. 6, pp. 440-448, 2008.

[123] M.-A. Cornier, D. Dabelea, T. L. Hernandez et al., "The metabolic syndrome," Endocrine Reviews, vol. 29, no. 7, pp. 777822, 2008.

[124] V. Vu, P. Bui, M. Eguchi, A. Xu, and G. Sweeney, "Globular adiponectin induces LKB1/AMPK-dependent glucose uptake via actin cytoskeleton remodeling," Journal of Molecular Endocrinology, vol. 51, no. 1, pp. 155-165, 2013.

[125] J. Song and J. E. Lee, "Adiponectin as a new paradigm for approaching Alzheimer's disease," Anatomy \& Cell Biology, vol. 46, no. 4, pp. 229-234, 2013.

[126] X. Mao, C. K. Kikani, R. A. Riojas et al., "APPL1 binds to adiponectin receptors and mediates adiponectin signalling and function," Nature Cell Biology, vol. 8, no. 5, pp. 516-523, 2006.

[127] T. Yamauchi, J. Kamon, H. Waki et al., "The fat-derived hormone adiponectin reverses insulin resistance associated with both lipoatrophy and obesity," Nature Medicine, vol. 7, no. 8, pp. 941-946, 2001.

[128] M. K. S. Leow, C. L. Addy, and C. S. Mantzoros, "Clinical review 159: human immunodeficiency virus/highly active antiretroviral therapy-associated metabolic syndrome: clinical presentation, pathophysiology, and therapeutic strategies," The Journal of Clinical Endocrinology \& Metabolism, vol. 88, no. 5, pp. 1961-1976, 2003. 
[129] N. Kubota, Y. Terauchi, T. Yamauchi et al., "Disruption of adiponectin causes insulin resistance and neointimal formation," The Journal of Biological Chemistry, vol. 277, no. 29, pp. 25863-25866, 2002.

[130] M. Okamoto, M. Ohara-Imaizumi, N. Kubota et al., "Adiponectin induces insulin secretion in vitro and in vivo at a low glucose concentration," Diabetologia, vol. 51, no. 5, pp. 827-835, 2008.

[131] N. Yamaguchi, T. Kukita, Y.-J. Li et al., "Adiponectin inhibits osteoclast formation stimulated by lipopolysaccharide from Actinobacillus actinomycetemcomitans," FEMS Immunology \& Medical Microbiology, vol. 49, no. 1, pp. 28-34, 2007.

[132] A. Hofman, A. Ott, M. M. B. Breteler et al., "Atherosclerosis, apolipoprotein E, and prevalence of dementia and Alzheimer's disease in the Rotterdam study," The Lancet, vol. 349, no. 9046, pp. 151-154, 1997.

[133] F. A. McAlister, K. B. Zarnke, N. R. C. Campbell et al., "The 2001 Canadian recommendations for the management of hypertension-part two: therapy," Canadian Journal of Cardiology, vol. 18, no. 6, pp. 625-641, 2002.

[134] K. Jandeleit-Dahm and M. E. Cooper, "Hypertension and diabetes," Current Opinion in Nephrology and Hypertension, vol. 11, no. 2, pp. 221-228, 2002.

[135] R. W. Schrier, R. O. Estacio, A. Esler, and P. Mehler, "Effects of aggressive blood pressure control in normotensive type 2 diabetic patients on albuminuria, retinopathy and strokes," Kidney International, vol. 61, no. 3, pp. 1086-1097, 2002.

[136] E. C. McNay, "The impact of recurrent hypoglycemia on cognitive function in aging," Neurobiology of Aging, vol. 26, supplement 1, pp. S76-S79, 2005.

[137] C. Weyer, R. L. Hanson, P. A. Tataranni, C. Bogardus, and R. E. Pratley, "A high fasting plasma insulin concentration predicts type 2 diabetes independent of insulin resistance: evidence for a pathogenic role of relative hyperinsulinemia," Diabetes, vol. 49, no. 12, pp. 2094-2101, 2000.

[138] D. J. Cox, B. P. Kovatchev, L. A. Gonder-Frederick et al., "Relationships between hyperglycemia and cognitive performance among adults with type 1 and type 2 diabetes," Diabetes Care, vol. 28, no. 1, pp. 71-77, 2005.

[139] K. Yaffe, T. Blackwell, A. M. Kanaya, N. Davidowitz, E. BarrettConnor, and K. Krueger, "Diabetes, impaired fasting glucose, and development of cognitive impairment in older women," Neurology, vol. 63, no. 4, pp. 658-663, 2004.

[140] A. Imagawa, T. Funahashi, T. Nakamura et al., "Elevated serum concentration of adipose-derived factor, adiponectin, in patients with type 1 diabetes," Diabetes Care, vol. 25, no. 9, pp. 1665-1666, 2002.

[141] M. Zhu, J. Miura, L. X. Lu et al., "Circulating adiponectin levels increase in rats on caloric restriction: the potential for insulin sensitization," Experimental Gerontology, vol. 39, no. 7, pp. 10491059, 2004.

[142] N. Stefan, J. C. Bunt, A. D. Salbe, T. Funahashi, Y. Matsuzawa, and P. Antonio Tataranni, "Plasma adiponectin concentrations in children: relationships with obesity and insulinemia," The Journal of Clinical Endocrinology \& Metabolism, vol. 87, no. 10, pp. 4652-4656, 2002.

[143] J. Krakoff, T. Funahashi, C. D. A. Stehouwer et al., "Inflammatory markers, adiponectin, and risk of type 2 diabetes in the Pima Indian," Diabetes Care, vol. 26, no. 6, pp. 1745-1751, 2003.

[144] R. S. Lindsay, T. Funahashi, R. L. Hanson et al., "Adiponectin and development of type 2 diabetes in the Pima Indian population," The Lancet, vol. 360, no. 9326, pp. 57-58, 2002.
[145] D. C. W. Lau, B. Dhillon, H. Yan, P. E. Szmitko, and S. Verma, "Adipokines: molecular links between obesity and atheroslcerosis," American Journal of Physiology: Heart and Circulatory Physiology, vol. 288, no. 5, pp. H2031-H2041, 2005.

[146] K. Hotta, T. Funahashi, Y. Arita et al., "Plasma concentrations of a novel, adipose-specific protein, adiponectin, in type 2 diabetic patients," Arteriosclerosis, Thrombosis, and Vascular Biology, vol. 20, no. 6, pp. 1595-1599, 2000.

[147] A. J. Hanley, L. E. Wagenknecht, J. M. Norris et al., "Adiponectin and the incidence of type 2 diabetes in Hispanics and African Americans: the IRAS Family study," Diabetes Care, vol. 34, no. 10, pp. 2231-2236, 2011.

[148] K. Hotta, T. Funahashi, N. L. Bodkin et al., "Circulating concentrations of the adipocyte protein adiponectin are decreased in parallel with reduced insulin sensitivity during the progression to type 2 diabetes in rhesus monkeys," Diabetes, vol. 50, no. 5 , pp. 1126-1133, 2001.

[149] J. V. Tu, "Reducing the global burden of stroke: INTERSTROKE," The Lancet, vol. 376, no. 9735, pp. 74-75, 2010.

[150] S. MacMahon, R. Peto, J. Cutler et al., "Blood pressure, stroke, and coronary heart disease-part 1: prolonged differences in blood pressure: prospective observational studies corrected for the regression dilution bias," The Lancet, vol. 335, no. 8692, pp. 765-774, 1990.

[151] M. F. O’Rourke and M. E. Safar, "Relationship between aortic stiffening and microvascular disease in brain and kidney: cause and logic of therapy," Hypertension, vol. 46, no. 1, pp. 200-204, 2005.

[152] C. Qiu, B. Winblad, and L. Fratiglioni, "The age-dependent relation of blood pressure to cognitive function and dementia," The Lancet Neurology, vol. 4, no. 8, pp. 487-499, 2005.

[153] J. A. Staessen, T. Richart, and W. H. Birkenhäger, "Less atherosclerosis and lower blood pressure for a meaningful life perspective with more brain," Hypertension, vol. 49, no. 3, pp. 389-400, 2007.

[154] M. Nagai, S. Hoshide, and K. Kario, "Hypertension and dementia," American Journal of Hypertension, vol. 23, no. 2, pp. 116-124, 2010.

[155] L. J. Launer, G. W. Ross, H. Petrovitch et al., "Midlife blood pressure and dementia: the Honolulu-Asia Aging study," Neurobiology of Aging, vol. 21, no. 1, pp. 49-55, 2000.

[156] L. J. Launer, K. Masaki, H. Petrovitch, D. Foley, and R. J. Havlik, "The association between midlife blood pressure levels and latelife cognitive function: the Honolulu-Asia Aging study," The Journal of the American Medical Association, vol. 274, no. 23, pp. 1846-1851, 1995.

[157] K. A. Jellinger and J. Attems, "Prevalence of dementia disorders in the oldest-old: an autopsy study," Acta Neuropathologica, vol. 119, no. 4, pp. 421-433, 2010.

[158] P. T. Nelson, E. Head, F. A. Schmitt et al., "Alzheimer's disease is not "brain aging": neuropathological, genetic, and epidemiological human studies," Acta Neuropathologica, vol. 121, no. 5, pp. 571-587, 2011.

[159] S. R. Waldstein, S. C. Rice, J. F. Thayer, S. S. Najjar, A. Scuteri, and A. B. Zonderman, "Pulse pressure and pulse wave velocity are related to cognitive decline in the Baltimore Longitudinal Study of Aging," Hypertension, vol. 51, no. 1, pp. 99-104, 2008.

[160] C. Qiu, B. Winblad, M. Viitanen, and L. Fratiglioni, "Pulse pressure and risk of alzheimer disease in persons aged 75 years and older: a community-based, longitudinal study," Stroke, vol. 34, no. 3, pp. 594-599, 2003. 
[161] A. Y. Lee, S.-H. Jeong, B. H. Choi, E. H. Sohn, and H. Chui, "Pulse pressure correlates with leukoaraiosis in Alzheimer disease," Archives of Gerontology and Geriatrics, vol. 42, no. 2, pp. 157-166, 2006.

[162] D. A. Nation, C. E. Wierenga, L. Delano-Wood et al., "Elevated pulse pressure is associated with age-related decline in language ability," Journal of the International Neuropsychological Society, vol. 16, no. 5, pp. 933-938, 2010.

[163] I. Skoog, B. Lernfelt, S. Landahl et al., "15-year longitudinal study of blood pressure and dementia," The Lancet, vol. 347, no. 9009, pp. 1141-1145, 1996.

[164] L. Molander, Y. Gustafson, and H. Lövheim, "Longitudinal associations between blood pressure and dementia in the very old," Dementia and Geriatric Cognitive Disorders, vol. 30, no. 3, pp. 269-276, 2010.

[165] P. L. Huang, Z. Huang, H. Mashimo et al., "Hypertension in mice lacking the gene for endothelial nitric oxide synthase," Nature, vol. 377, no. 6546, pp. 239-242, 1995.

[166] T. J. Guzik, E. Black, and N. E. West, "Relationship between the G894T polymorphism (Glu 298 Asp variant) in endothelial nitric oxide synthase and nitric oxide-mediated endothelial function in human atherosclerosis," American Journal of Medical Genetics, vol. 100, no. 2, pp. 130-137, 2001.

[167] W. Zhu, K. K. Y. Cheng, P. M. Vanhoutte, K. S. L. Lam, and A. Xu, "Vascular effects of adiponectin: molecular mechanisms and potential therapeutic intervention," Clinical Science, vol. 114, no. 5-6, pp. 361-374, 2008.

[168] R. Ouedraogo, Y. Gong, B. Berzins et al., "Adiponectin deficiency increases leukocyte-endothelium interactions via upregulation of endothelial cell adhesion molecules in vivo," The Journal of Clinical Investigation, vol. 117, no. 6, pp. 1718-1726, 2007.

[169] R. Shibata, N. Ouchi, S. Kihara, K. Sato, T. Funahashi, and K. Walsh, "Adiponectin stimulates angiogenesis in response to tissue ischemia through stimulation of AMP-activated protein kinase signaling," The Journal of Biological Chemistry, vol. 279, no. 27, pp. 28670-28674, 2004.

[170] H. Chen, M. Montagnani, T. Funahashi, I. Shimomura, and M. J. Quon, "Adiponectin stimulates production of nitric oxide in vascular endothelial cells," The Journal of Biological Chemistry, vol. 278, no. 45, pp. 45021-45026, 2003.

[171] N. Ouchi, H. Kobayashi, S. Kihara et al., "Adiponectin stimulates angiogenesis by promoting cross-talk between AMP-activated protein kinase and Akt signaling in endothelial cells," The Journal of Biological Chemistry, vol. 279, no. 2, pp. 1304-1309, 2004.

[172] H. Kobayashi, N. Ouchi, S. Kihara et al., "Selective suppression of endothelial cell apoptosis by the high molecular weight form of adiponectin," Circulation Research, vol. 94, no. 4, pp. e27-e31, 2004.

[173] A. Takahashi, Y. Kureishi, J. Yang et al., "Myogenic Akt signaling regulates blood vessel recruitment during myofiber growth," Molecular and Cellular Biology, vol. 22, no. 13, pp. 4803-4814, 2002.

[174] K. Mahadev, X. Wu, S. Donnelly, R. Ouedraogo, A. D. Eckhart, and B. J. Goldstein, "Adiponectin inhibits vascular endothelial growth factor-induced migration of human coronary artery endothelial cells," Cardiovascular Research, vol. 78, no. 2, pp. 376-384, 2008.

[175] B. J. Goldstein, R. G. Scalia, and X. L. Ma, "Protective vascular and myocardial effects of adiponectin," Nature Clinical Practice: Cardiovascular Medicine, vol. 6, no. 1, pp. 27-35, 2009.
[176] M. Takaoka, D. Nagata, S. Kihara et al., "Periadventitial adipose tissue plays a critical role in vascular remodeling," Circulation Research, vol. 105, no. 9, pp. 906-911, 2009.

[177] B. J. Goldstein and R. Scalia, "Adiponectin: a novel adipokine linking adipocytes and vascular function," The Journal of Clinical Endocrinology \& Metabolism, vol. 89, no. 6, pp. 2563-2568, 2004.

[178] T. G. Beach, J. R. Wilson, L. I. Sue et al., "Circle of Willis atherosclerosis: association with Alzheimer's disease, neuritic plaques and neurofibrillary tangles," Acta Neuropathologica, vol. 113, no. 1, pp. 13-21, 2007.

[179] H. C. Stary, "Natural history and histological classification of atherosclerotic lesions an update," Arteriosclerosis, Thrombosis, and Vascular Biology, vol. 20, no. 5, pp. 1177-1178, 2000.

[180] H. C. Stary, A. B. Chandler, R. E. Dinsmore et al., "A definition of advanced types of atherosclerotic lesions and a histological classification of atherosclerosis: a report from the Committee on Vascular Lesions of the Council on Arteriosclerosis, American Heart Association," Circulation, vol. 92, no. 5, pp. 1355-1374, 1995.

[181] E. S. C. Korf, L. R. White, P. Scheltens, and L. J. Launer, "Midlife blood pressure and the risk of hippocampal atrophy: the Honolulu Asia Aging study," Hypertension, vol. 44, no. 1, pp. 29-34, 2004.

[182] J.-O. Deguchi, E. Aikawa, P. Libby et al., "Matrix metalloproteinase-13/collagenase-3 deletion promotes collagen accumulation and organization in mouse atherosclerotic plaques," Circulation, vol. 112, no. 17, pp. 2708-2715, 2005.

[183] J.-O. Deguchi, M. Aikawa, C.-H. Tung et al., "Inflammation in atherosclerosis: visualizing matrix metalloproteinase action in macrophages in vivo," Circulation, vol. 114, no. 1, pp. 55-62, 2006.

[184] C. M. Dollery, C. A. Owen, G. K. Sukhova, A. Krettek, S. D. Shapiro, and P. Libby, "Neutrophil elastase in human atherosclerotic plaques production by macrophages," Circulation, vol. 107, no. 22, pp. 2829-2836, 2003.

[185] S. Larionov, O. Dedeck, G. Birkenmeier, and D. R. Thal, "Expression of $\alpha 2$-macroglobulin, neutrophil elastase, and interleukin- $1 \alpha$ differs in early-stage and late-stage atherosclerotic lesions in the arteries of the circle of Willis," Acta Neuropathologica, vol. 113, no. 1, pp. 33-43, 2007.

[186] J. Liang, E. Liu, Y. Yu et al., "Macrophage metalloelastase accelerates the progression of atherosclerosis in transgenic rabbits," Circulation, vol. 113, no. 16, pp. 1993-2001, 2006.

[187] S. H. Han, M. J. Quon, J.-A. Kim, and K. K. Koh, "Adiponectin and cardiovascular disease: response to therapeutic interventions," Journal of the American College of Cardiology, vol. 49, no. 5, pp. 531-538, 2007.

[188] N. Ouchi, S. Kihara, Y. Arita et al., "Adiponectin, an adipocytederived plasma protein, inhibits endothelial NF- $\kappa$ B signaling through a cAMP-dependent pathway," Circulation, vol. 102, no. 11, pp. 1296-1301, 2000.

[189] N. Ouchi, S. Kihara, Y. Arita et al., "Novel modulator for endothelial adhesion molecules: adipocyte-derived plasma protein adiponectin," Circulation, vol. 100, no. 25, pp. 2473-2476, 1999.

[190] N. Ouchi, S. Kihara, Y. Arita et al., "Adipocyte-derived plasma protein, adiponectin, suppresses lipid accumulation and class A scavenger receptor expression in human monocyte-derived macrophages," Circulation, vol. 103, no. 8, pp. 1057-1063, 2001.

[191] L. M. Allan, E. N. Rowan, M. J. Firbank et al., "Long term incidence of dementia, predictors of mortality and pathological 
diagnosis in older stroke survivors," Brain, vol. 134, no. 12, pp. 3716-3727, 2011.

[192] D. Leys, H. Hénon, M.-A. Mackowiak-Cordoliani, and F. Pasquier, "Poststroke dementia," The Lancet Neurology, vol. 4, no. 11, pp. 752-759, 2005.

[193] S. T. Pendlebury and P. M. Rothwell, "Prevalence, incidence, and factors associated with pre-stroke and post-stroke dementia: a systematic review and meta-analysis," The Lancet Neurology, vol. 8, no. 11, pp. 1006-1018, 2009.

[194] C. Reitz, M. J. Bos, A. Hofman, P. J. Koudstaal, and M. M. B. Breteler, "Prestroke cognitive performance, incident stroke, and risk of dementia: the Rotterdam study," Stroke, vol. 39, no. 1, pp. 36-41, 2008.

[195] P. Schaapsmeerders, N. A. Maaijwee, E. J. van Dijk et al., "Longterm cognitive impairment after first-ever ischemic stroke in young adults," Stroke, vol. 44, no. 6, pp. 1621-1628, 2013.

[196] E. Kokmen, J. P. Whisnant, W. M. O'Fallon, C.-P. Chu, and C. M. Beard, "Dementia after ischemic stroke: a population-based study in Rochester, Minnesota (1960-1984)," Neurology, vol. 46, no. 1, pp. 154-159, 1996.

[197] I. Grant, J. Rochford, T. Fleming, and A. Stunkard, "A neuropsychological assessment of the effects of moderate marihuana use," Journal of Nervous and Mental Disease, vol. 156, no. 4, pp. 278-280, 1973.

[198] D. J. Stott, P. Welsh, A. Rumley et al., "Adipocytokines and risk of stroke in older people: a nested case-control study," International Journal of Epidemiology, vol. 38, no. 1, pp. 253-261, 2009.

[199] C. Prugger, G. Luc, B. Haas et al., "Adipocytokines and the risk of ischemic stroke: the PRIME study," Annals of Neurology, vol. 71, no. 4, pp. 478-486, 2012.

[200] C. Savopoulos, K. Michalakis, M. Apostolopoulou, A. Miras, and A. Hatzitolios, "Adipokines and stroke: a review of the literature," Maturitas, vol. 70, no. 4, pp. 322-327, 2011.

[201] B. J. Kim, S.-H. Lee, W.-S. Ryu, C. K. Kim, and B.-W. Yoon, "Adipocytokines and ischemic stroke: differential associations between stroke subtypes," Journal of the Neurological Sciences, vol. 312, no. 1-2, pp. 117-122, 2012.

[202] Y. Nakamura, K. Shimada, D. Fukuda et al., "Implications of plasma concentrations of adiponectin in patients with coronary artery disease," Heart, vol. 90, no. 5, pp. 528-533, 2004.

[203] F. Otsuka, S. Sugiyama, S. Kojima et al., "Plasma adiponectin levels are associated with coronary lesion complexity in men with coronary artery disease," Journal of the American College of Cardiology, vol. 48, no. 6, pp. 1155-1162, 2006.

[204] M. Kumada, S. Kihara, S. Sumitsuji et al., "Association of hypoadiponectinemia with coronary artery disease in men," Arteriosclerosis, Thrombosis, and Vascular Biology, vol. 23, no. 1, pp. 85-89, 2003.

[205] R. Shibata, K. Sato, D. R. Pimentel et al., "Adiponectin protects against myocardial ischemia-reperfusion injury through AMPK- and COX-2-dependent mechanisms," Nature Medicine, vol. 11, no. 10, pp. 1096-1103, 2005.

[206] L. Tao, X. Jiao, E. Gao et al., "Nitrative inactivation of thioredoxin-1 and its role in postischemic myocardial apoptosis," Circulation, vol. 114, no. 13, pp. 1395-1402, 2006.

[207] R. Shibata, N. Ouchi, M. Ito et al., "Adiponectin-mediated modulation of hypertrophic signals in the heart," Nature Medicine, vol. 10, no. 12, pp. 1384-1389, 2004.

[208] Y. S. Jung, S. K. Ha, S. D. Kim, S. H. Kim, D. J. Lim, and J. I. Choi, "The role of adiponectin in secondary inflammatory reaction in cerebral ischemia," Journal of Cerebrovascular and Endovascular Neurosurgery, vol. 15, no. 3, pp. 171-176, 2013.

[209] M. Nishimura, Y. Izumiya, A. Higuchi et al., "Adiponectin prevents cerebral ischemic injury through endothelial nitric oxide synthase-dependent mechanisms," Circulation, vol. 117, no. 2, pp. 216-223, 2008.

[210] W. Song, T. Huo, F. Guo et al., "Globular adiponectin elicits neuroprotection by inhibiting NADPH oxidase-mediated oxidative damage in ischemic stroke," Neuroscience, vol. 248, pp. 136-144, 2013.

[211] L. Shen, J. Miao, F. Yuan et al., "Overexpression of adiponectin promotes focal angiogenesis in the mouse brain following middle cerebral artery occlusion," Gene Therapy, vol. 20, no. 1, pp. 93-101, 2013.

[212] D. Nagata, M. Mogi, and K. Walsh, "AMP-activated protein kinase (AMPK) signaling in endothelial cells is essential for angiogenesis in response to hypoxic stress," The Journal of Biological Chemistry, vol. 278, no. 33, pp. 31000-31006, 2003.

[213] N. Ouchi, R. Shibata, and K. Walsh, "AMP-activated protein kinase signaling stimulates VEGF expression and angiogenesis in skeletal muscle," Circulation Research, vol. 96, no. 8, pp. 838846, 2005. 

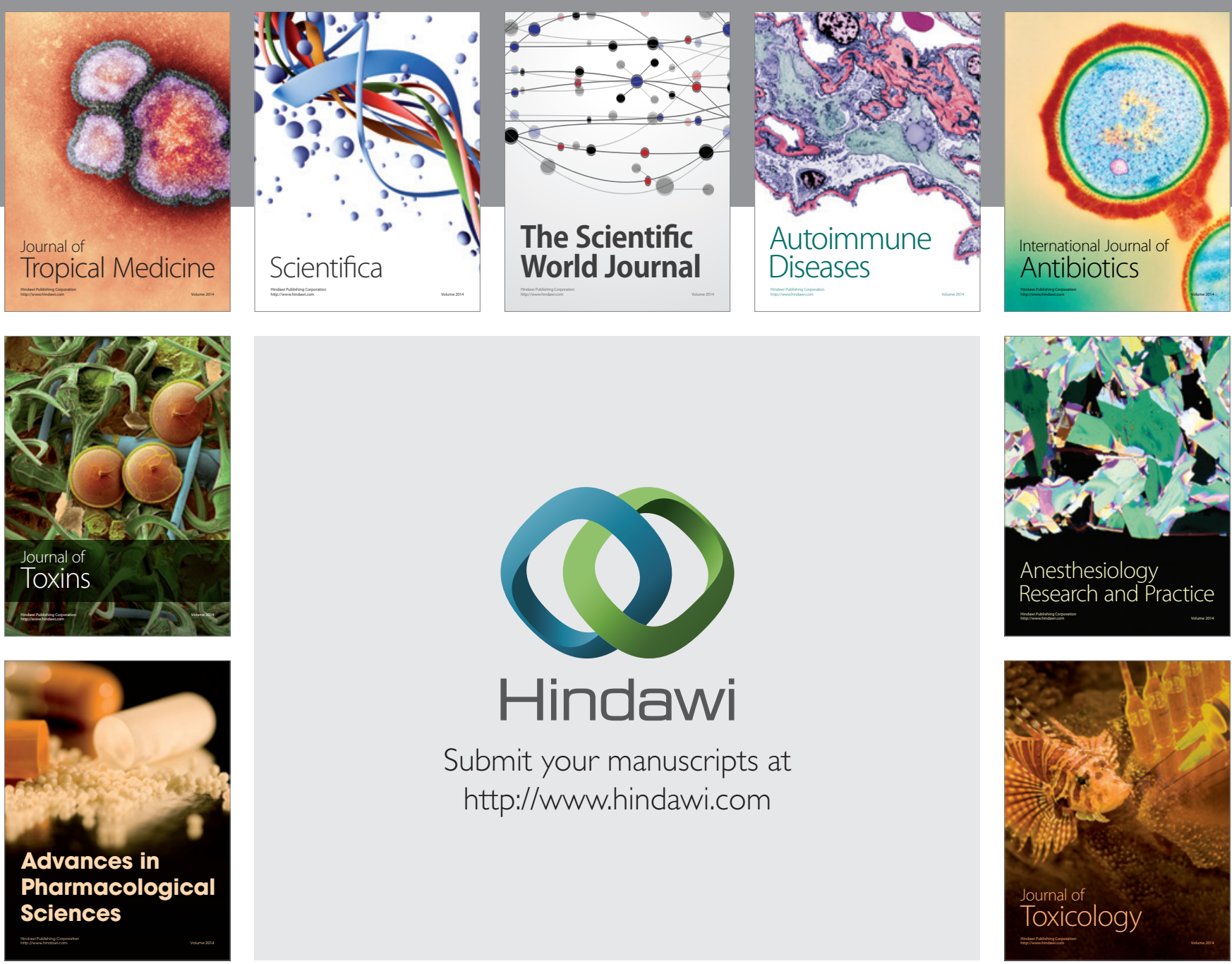

\section{Hindawi}

Submit your manuscripts at

http://www.hindawi.com
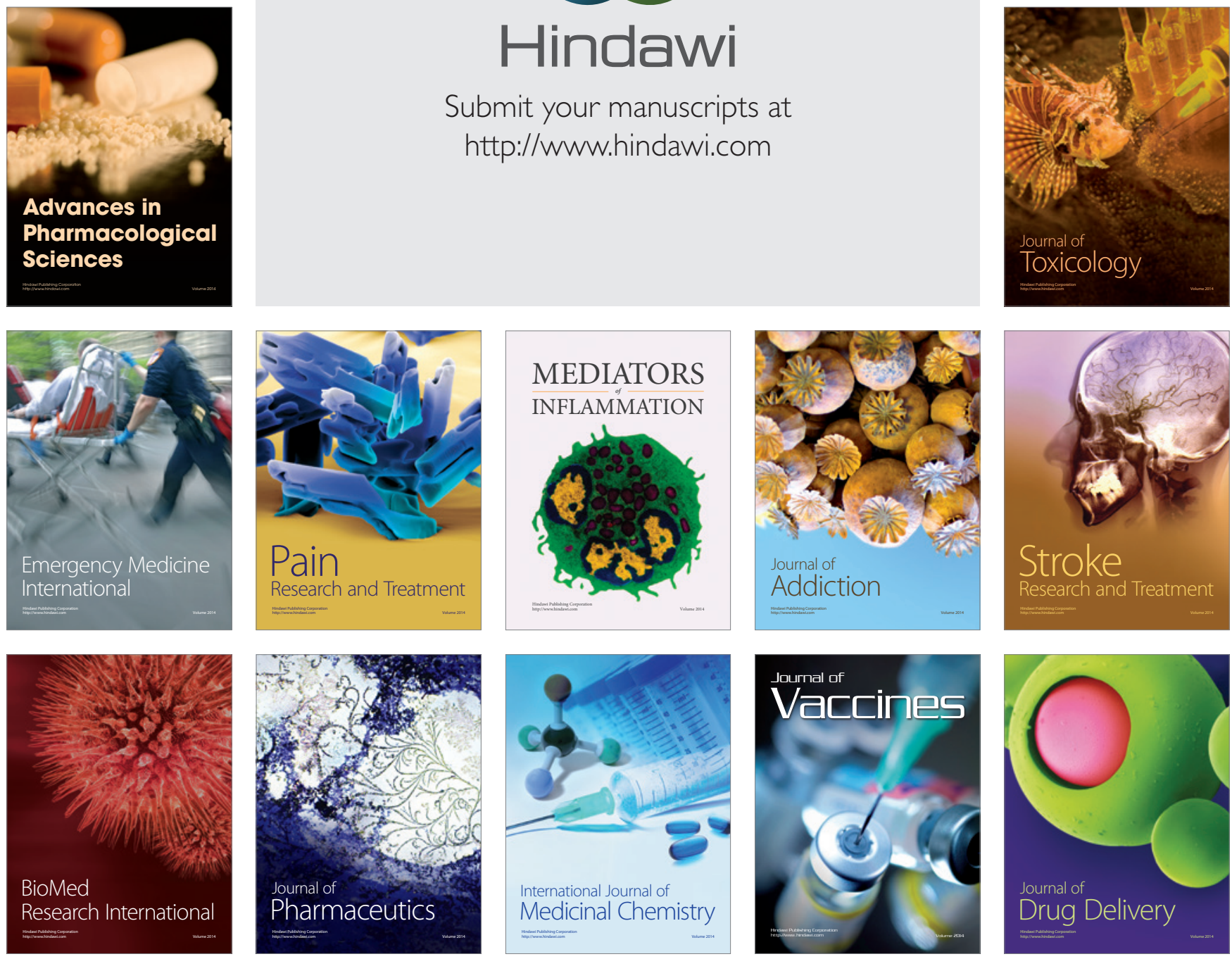